\title{
Duodenal ulceration following gastroduodenal artery embolization with coils
}

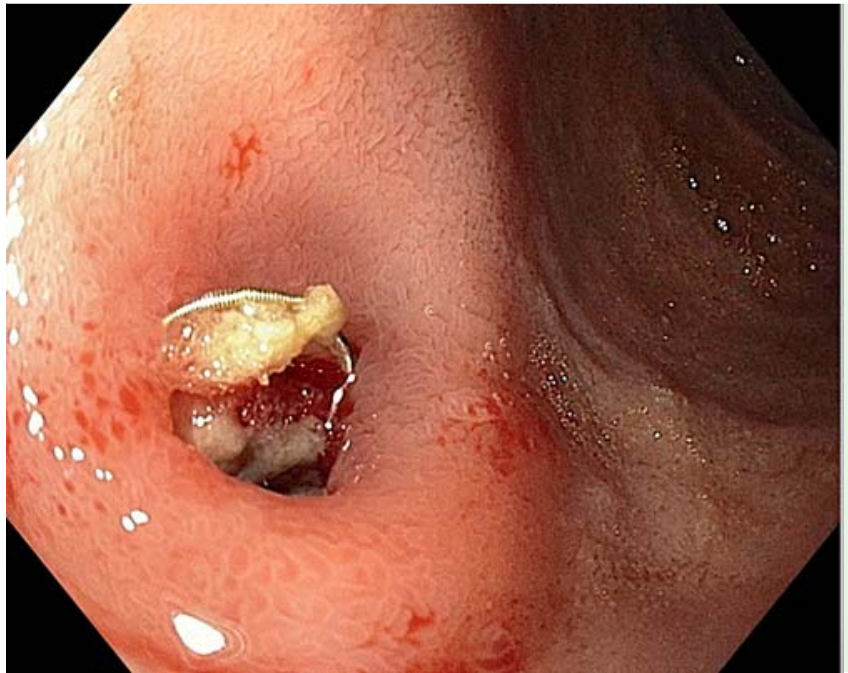

Fig. 1 Endoscopic appearance of the previously placed coil eroding the duodenal mucosa, with surrounding ulceration.

An 84-year-old woman was admitted to our department with epigastric pain, nausea, and vomiting. The patient had been treated for upper gastrointestinal bleeding and hemorrhagic shock 2 months earlier, with a hemoglobin level of $6.3 \mathrm{~g} / \mathrm{dL}$. The source of the bleeding was not found during several upper gastrointestinal procedures (esophagogastroduodenoscopy [EGD]), and empiric embolization of the gastroduodenal artery was performed with four fibered $0.6 \times 14-\mathrm{cm}$ coils (Azur Hydrocoils; Terumo Interventional Systems, Tokyo, Japan) and eight $0.4 \times 3.7-\mathrm{cm}$ microcoils (VortX Diamond; Boston Scientific, Natick, Massachusetts, USA). In addition, the patient received a transfusion of 5 units of blood. The subsequent clinical course was uneventful.

At the time of the current admission, examination revealed epigastric tenderness without signs of peritonitis. Blood tests revealed no abnormalities. EGD revealed a foreign body (metallic coil) eroding the duodenal mucosa, with mucosal inflammation and thinning of the mucosa overlying the metallic coil ( $\bullet$ Fig. 1). There were no signs of bleeding. A duodenal fistula was suspected, but an upper gastro- intestinal series revealed no signs of a fistula ( Fig. 2). The coil was left in situ because of concern for recurrent bleeding. Oral omeprazole was prescribed for 1 month at a dosage of $20 \mathrm{mg}$ twice a day. After 1 month, the patient was feeling better, with resolution of the abdominal pain, nausea, and vomiting. EGD and abdominal radiography were performed. The coil had separated out, and no pathological changes were found in the duodenum during EGD ( $\bullet$ Fig. 3) and abdominal radiography ( $\bullet$ Fig.4).

Angiographic embolization can be the best alternative for the treatment of massive hemorrhage if the patient has severe co-morbidities and contraindications at the time of surgery [1]. The most feared complication of embolization is migration of the coil, which has been reported to occur in up to $3 \%$ of cases [2]. Only two previous reports describing vascular coil erosion into the duodenum have been published $[3,4]$. No treatment strategy has been established for migrated coils.

\section{Endoscopy_UCTN_Code_CPL_1AK_2AI}

Competing interests: None

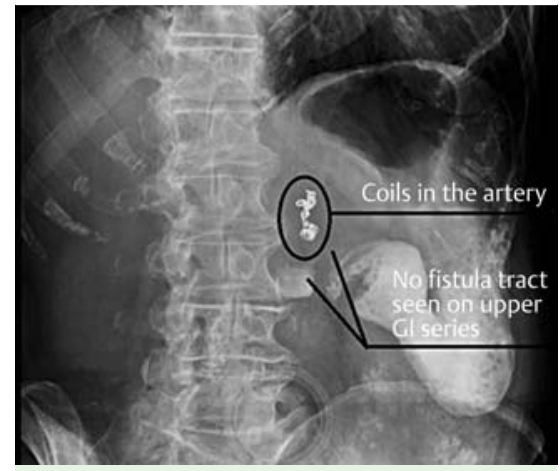

Fig. 2 Coils are seen in the artery (oval), with no fistula found on an upper gastrointestinal series (oblique lines).

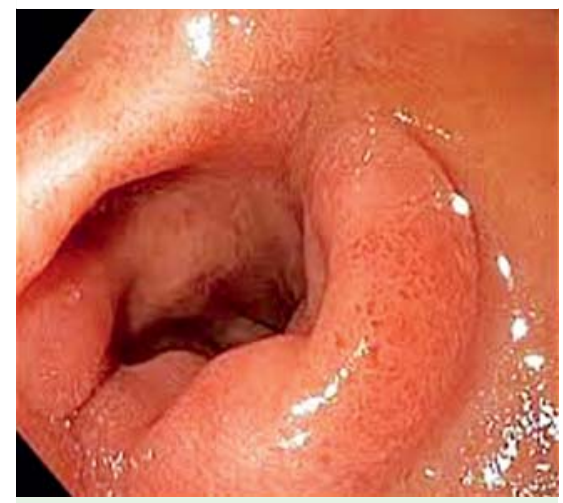

Fig. 3 No pathology is seen during upper gastrointestinal endoscopy at 1 month.

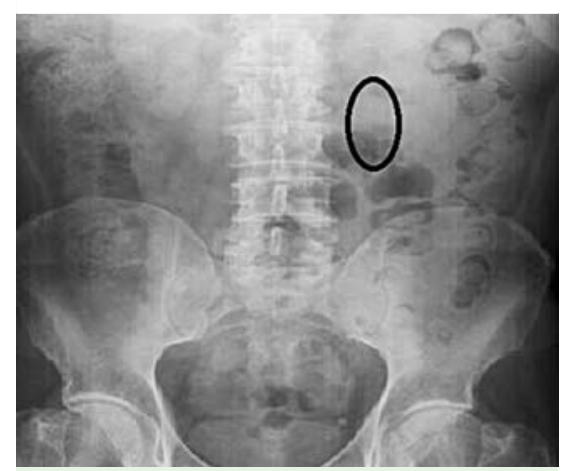

Fig.4 No foreign bodies (coils) are seen on abdominal X-ray film (oval). 
Audrius Dulskas ${ }^{1}$, Giedre Rudinskaite ${ }^{1}$, Romualdas Maskelis ${ }^{1}$, Zygimantas Kuliesius ${ }^{2}$, Ricardo Escalante ${ }^{3}$, Narimantas Samalavicius ${ }^{1,4}$

${ }^{1}$ Department of Abdominal and General Surgery and Oncology, National Cancer Institute, Vilnius, Lithuania

2 Republican Vilnius University Hospital, Vilnius, Lithuania

${ }^{3}$ Department of Surgery, Medical Center of Loira, Caracas, Venezuela

${ }^{4}$ Center of Oncosurgery, National Cancer Institute, Clinic of Internal Medicine, Family Practice and Oncology, Faculty of Medicine, Vilnius University, Vilnius, Lithuania

\section{References}

1 Dixon S, Chan V, Shrivastava Vet al. Is there a role for empiric gastroduodenal artery embolization in the management of patients with active upper GI hemorrhage? Cardiovasc Intervent Radiol 2013; 36: 970-977

2 Leyon JJ, Littlehales T, Rangarajan B et al. Endovascular embolization: review of currently available embolization agents. Curr Probl Diagn Radiol 2014; 43: 35-53

3 Park $\mathrm{CH}$, Bae SH, Kim HY et al. Hepatobiliary and pancreatic: bleeding duodenal ulcer associated with coil migration after transarterial chemoembolization and radiotherapy. J Gastroenterol Hepatol 2014; 29: 897

4 Jaurigue MM, Snyder M, Cannon M. Recurrent upper GI bleeding secondary to coil migration in a patient with known NSAIDinduced peptic ulcer disease. Gastrointest Endosc 2014; 79: 1004

\section{Bibliography}

Dol http://dx.doi.org/

10.1055/s-0034-1393143

Endoscopy 2015; 47: E488-E489

(c) Georg Thieme Verlag KG

Stuttgart · New York

ISSN 0013-726X

\section{Corresponding author}

\section{Audrius Dulskas}

Department of Abdominal and General Surgery and Oncology

National Cancer Institute

1 Santariskiu Street

Vilnius LT-08406

Lithuania

Fax: +370-5-2310315

audrius.dulskas@gmail.com 